\title{
Membrana neuronal y envejecimiento. Aspectos electrofisiológicos
}

\author{
C. Solsona-Sancho, J.M.V. Blasi-Cabús
}

\author{
NEURONE MEMBRANE AND AGING. ELECTROPHYSIOLOGICAL ASPECTS
}

\begin{abstract}
Summary. Introduction. The cell membranes are formed of lipids and proteins. Because of their hydrophobic nature, phospholipids separate the intracellular from the extracellular medium. Development. The extracellular medium is a solution enriched with sodium ions, whilst the intracellular medium is rich in potassium ions. In accordance with the laws of chemistry, the asymmetric distribution of ions causes a small potential difference between the inside and outside of the cell. All the cells of the human body show this small difference in potential of about -60 mV. Another component of the cell membranes are proteins. Some of these -the ion pumps or ATPases-maintain the asymmetric distribution of the ions. Other membrane proteins - the ion channels-permit the selective passage of ions between the intracellularand extracellularmedia. Electrophysiologicaltechniques (patchclamp) appliedatacellularlevel allow us to measure the passage of ions across a single molecule. Each ion channel permits the passage of a single ionic species. The cells contain ion channels which are transiently permeable to the ions of sodium, potassium, calcium and chlorine. One of the characteristic properties of neurons is that they are excitable cells. Neuronal excitability depends on the ion channels. The neurons show different electrical behavior during the different phases of life. The changes in the electrical activity of the neurons are determined by the activity of the ion channels and their interaction with the liquid surrounding them. Conclusions. Investigations are being done to relate the changes in behavior of the ion channels with the process of aging of the neurone membranes [REV NEUROL 1999; 29: 1083-8]. Key words. Aging. Ion channels. Neurodegeneration.
\end{abstract}

\section{INTRODUCCIÓN}

La célula es la unidad funcional y estructural de todos los organismos. En el siglo pasado la teoría celular estableció que el cuerpo humano está formado por un gran número de unidades funcionales autónomas que son las células. También se fundamentó en el concepto de que la célula es la unidad donde se manifiesta la patología, de manera que las enfermedades corresponden a cambios morfológicos y funcionales de las células. Todas las células quedan rodeadas por una membrana que las mantiene aisladas del medio en el que se encuentran. La unidad estructural y funcional de las células se mantiene gracias a esta membrana celular o membrana plasmática que es responsable de mantener una composición interna distinta a la externa. Sin embargo, en el interior de las células también encontramos otras membranas que forman parte de los orgánulos intracelulares como el aparato de Golgi, las mitocondrias, el retículo endoplásmico o la cubierta del núcleo celular. La organización y composición básica de la membrana celular no varía de célula a célula y es también muy parecida entre la membrana plasmática y las membranas intracelulares. En el presente artículo revisaremos especialmente los fenómenos relacionados con la membrana plasmática y sólo nos referiremos ocasionalmente a la membranas que forman los órganos intracelulares.

La membrana neuronal define las propiedades funcionales de las neuronas. El cambio en la composición de las membranas neuronales acarrea el cambio de las propiedades funcionales de las neuronas. Las membranas neuronales varían su composición y propiedades a lo largo de la vida. No son iguales las membranas neuronales durante el desarrolloque durante el envejecimiento. La mayor parte de las investigaciones recientes en el ámbito de las neurociencias están orientadas hacia la identificación de las distintas moléculas que forman la membrana neuronal, así como a establecer su importancia funcional y su relación con las enfermedades neurodegenerativas.

Recibido: 10.11.98. Recibidoen versión revisada: 26.05.99. Aceptado: 28.05.99. Laboratorio de Neurobiología Celular y Molecular. Departamento de Biología Celular y Anatomía Patológica. Facultat de Medicina. Hospital de Bellvitge. Universitat de Barcelona. Barcelona, España.

Correspondencia: Prof. Carles Solsona. Laboratori de Neurobiologia Cel-lular i Molecular. Departament de Biologia Cel-lular i Anatomia Patologica. Facultat de Medicina-Campus de Bellvitge. Feixa Llarga, s/n. E-08907 L'Hospitalet de Ll., Barcelona.Fax: +3493 402 4273. E-mail: solsona@ bellvitge.bvg.ub.es C 1999, REVISTA DE NEUROLOGÍA

\section{ESTRUCTURA Y FUNCIÓN DE LAS MEMBRANAS CELULARES}

Todas las membranas celulares tienen una estructura común. Se trata de una película extraordinariamente delgada de lípidos que contiene proteínas. Las interacciones entre las moléculas lipídicas, y entre éstas y las proteínas son de tipo no covalente. Así, de esta manera las fuerzas que se establecen entre las moléculas constitutivas de las membranas son relativamente débiles. Por tanto, las membranas celulares son estructuras fluidas y dinámicas, las moléculas que la forman tienen movilidad lateral y se adaptan a los cambios mecánicos que se producen en su entorno. Las moléculas lipídicas se organizan (Fig. 1) en una doble capa de un grosor de $5 \mathrm{~nm}\left(1 \mathrm{~nm}=10^{-3} \mu \mathrm{m}=10^{-6} \mathrm{~mm}=10^{-9} \mathrm{~m}\right)$. La naturaleza lipídica de las membranas celulares les confiere una muy baja permeabilidad al paso de moléculas hidrosolubles. El transporte de la mayoría de las moléculas a través de la membrana debe realizarse a través de las proteínas específicas de la membrana plasmática. Muchas de las proteínas de la membrana plasmática están insertadas en la bicapa lipídica (Figs. 1 y 2), exponiendo una parte a la superficie extracelular y otra hacia el interior de la célula, por ello se las describe como proteínas integrales de membrana. Las proteínas integrales de membrana pueden estar especializadas en funciones de transporte o bien ser receptores de señales procedentes del medio extracelular e iniciar una cascada de reacciones químicas que generarán la respuesta celular. En la membrana se pueden encontrar otras proteínas, las proteínas asociadas o periféricas, que están situadas en contacto con la bicapa lipídica sin atravesarla; su función es de tipo mecánico y la continuidad de la membrana con otros componentes del armazón celular (citoesqueleto) o de elementos de la matriz extracelular.

La estructura y composición de las dos capas de lípidos de las membranas celulares no es simétrica, ya que cada una tiene funciones distintas. En general, las partes glicosiladas (glicoproteínas y glicolípidos) de las membranas están orientadas hacia la superficie encarada hacia el espacio extracelular.

Una de las funciones asociadas a las membranas celulares es mantener una composición iónica distinta entre el interior y el exterior de la célula, transportando solutos específicos como aminoácidos, iones o azúcares simples. Otra función de la membrana plasmática es la recepción de señales procedentes de otras 


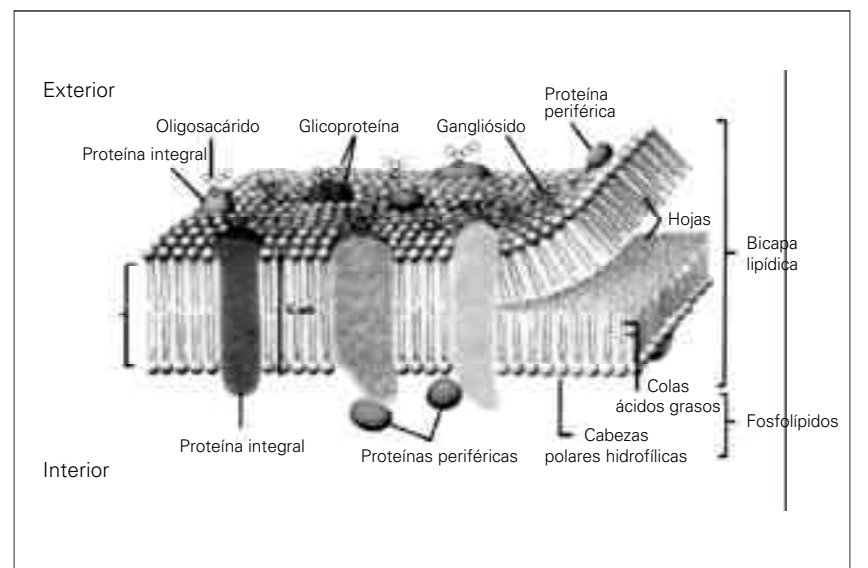

Figura 1. Estructura molecular general de las membranas biológicas. La bicapa lipídica constituye la estructura básica de las membranas celulares. Los fosfolípidos se orientan de forma que las cabezas polares quedan ex puestas en las superficies interna y externa de las membranas. Por el contrario, las cadenas de los ácidos grasos quedan orientadas hacia el interior de las membranas, y por tanto es una zona muy hidrofóbica. Las proteínas de la membrana quedan sumergidas en la bicapa lipídica, presentando movimientos laterales, de forma parecida al desplazamiento de un iceberg en el océano. La mayoría de las proteínas integrales de la membrana son glicoproteínas, es decir, sus cadenas peptídicas tienen asociados oligosacáridos. La parte glicídica de las glicoproteínas está orientada hacia el espacio extracelular. Los oligosacáridos también pueden asociarse a algunos lípidos, formando los gangliósidos. Además de las proteínas integrales de membrana, se encuentran proteínas que no atraviesan la membrana lipídica constituyendo las proteínas asociadas o periféricas. Las proteínas asociadas situadas en la parte interna de la célula establecen el nexo de unión entre el citoesqueleto (filamentos y microtúbulos) y la membrana celular [2].

células. Algunas proteínas de membrana son sensibles a señales extracelulares, las cuales inducen cambios en la actividad de las células. Estas proteínas con capacidad de reconocimiento de las señales externas son los receptores de membrana.

\section{COMPOSICIÓN DE LAS MEMBRANAS CELULARES [1,2]}

Como se ha mencionado anteriormente, las membranas están formadas por proteínas y lípidos. Más de la mitad de las moléculas que forman las membranas son lípidos; se calcula que existen $5.10^{6}$ moléculas de lípidos por $\mu \mathrm{m}^{2}$ y del orden de $10^{9}$ moléculas de lípidos en la membrana plasmática de una célula animal de pequeño tamaño. Los lípidos presentes en la membrana plasmática de la célula animal son los fosfolípidos, el colesterol y los glicolípidos. Desde el punto de vista químico los lípidos son moléculas anfipáticas, también llamadas anfifílicas. Una molécula anfipática tiene a la vez una parte hidrofílica (denominada también parte polar) y una parte hidrofóbica (parte no polar).

\section{Fosfolípidos}

Los lípidos más abundantes en las membranas celulares son los fosfolípidos. Los fosfolípidos son moléculas con dos regiones claramente diferenciadas, hay una 'cabeza' (la parte polar) y dos 'colas' (parte no polar) (Fig. 3); las colas están formadas por cadenas de ácidos grasos que contienen de 12 a 24 átomos de carbono. Generalmente una de las colas tiene uno o más dobles enlaces (ácido graso insaturado) mientras que la otra cola no presenta dobles enlaces (ácido graso saturado). Los dobles enlaces de las 'colas' de ácidos grasos insaturados tienen un efecto de torsión sobre la molécula, de forma que se produce un pliegue molecular. Las diferencias en el tamaño y el grado de insaturación de los

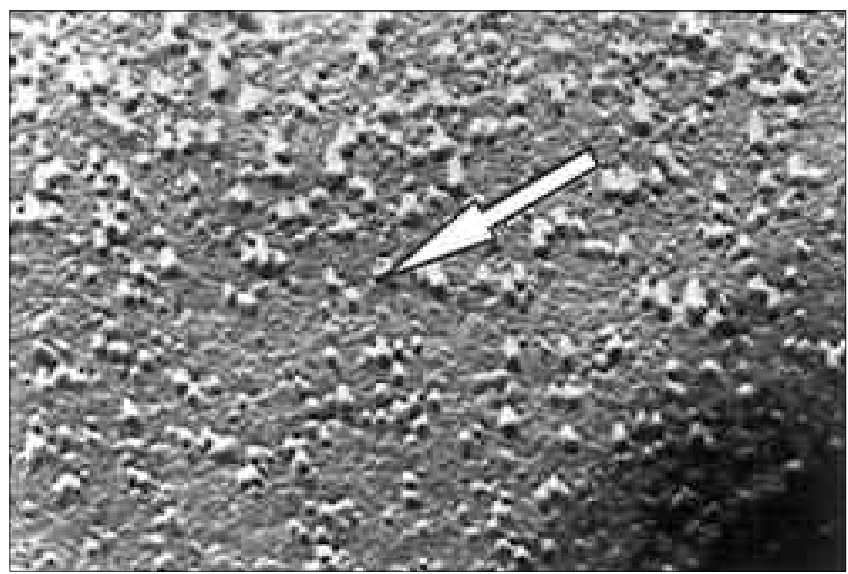

Figura 2. Estructura de las membranas celulares. La criofractura es una técnica que permite observar las superficies internas de las membranas celulares. Los tejidos se sumergen en gases líquidos a temperaturas cercanas a los $-200^{\circ} \mathrm{C}$. Las células congeladas se golpean suavemente de manera que se rompen. Las membranas celulares se fracturan por el plano que separa las dos capas lipídicas, de las cuales se obtienen moldes, que finalmente se observan al microscopio electrónico. La superficie lisa corresponde a las moléculas de fosfolípidos, mientras que la protrusiones (señaladas con la flecha) corresponden a la proteínas integrales de membrana. El tamaño de las proteínas integrales de membrana es de algunos nanómetros de diámetro.

ácidos grasos de las colas determinan las interacciones entre las moléculas de fosfolípidos vecinas y consecuentemente el grado de empaquetamiento de los fosfolípidos en las membranas celulares. El cambio en el número de átomos de carbono y la posición de los dobles enlaces modifica algunas de las propiedades de las membranas, como por ejemplo la fluidez que corresponde al grado de libertad con que se puede mover lateralmente una molécula.

La 'cabeza' de los fosfolípidos está formada por colina, fosfato y glicerol (Fig. 3). La 'cabeza' de los fosfolípidos contiene dos componentes que le proporcionan la parte polar. Una molécula polar es la que, siendo eléctricamente neutra, tiene sus cargas distribuidas asimétricamente, el paradigma es el agua. La 'cabeza' de los fosfolípidos es la zona polar puesto que contiene cargas positivas y negativas ligadas al fosfato y a la colina, respectivamente. El fosfato proporciona la carga negativa, mientras que la carga positiva la proporciona la colina, que contiene un nitrógeno unido a cuatro átomos de carbono.

La colina de las cabezas polares de los fosfolípidos de las membranas plasmáticas puede ser sustituida por otras moléculas como la etanolamina o la serina. Los fosfolípidos mayoritarios en las células eucariotas son: fosfatidilcolina, fosfatidilserina, fosfatidiletanolamina y la esfingomielina. Otros fosfolípidos son muy minoritarios como los fosfolípidos de inositol, pero desempeñan un papel funcional muy importante, ya que estas pequeñas cantidades son capaces de actuar como señales celulares que activan reacciones metabólicas en cadena.

Los fosfolípidos se disponen en la membrana celular formando dos capas, la parte polar está orientada hacia la superficie de la membrana, mientras que la parte apolar se orienta hacia el interior de la membrana. Sabemos que los fosfolípidos tienden espontáneamente a tomar esta disposición molecular. Cuando se mezclan fosfolípidos en una solución acuosa en el tubo de ensayo, se forman espontáneamente pequeñas esferas (liposomas) de una estructura igual a la de las membranas celulares.

\section{Colesterol}

Respecto al colesterol, debemos señalar que puede representar hasta una cuarta parte del total de lípidos presentes en la membra- 


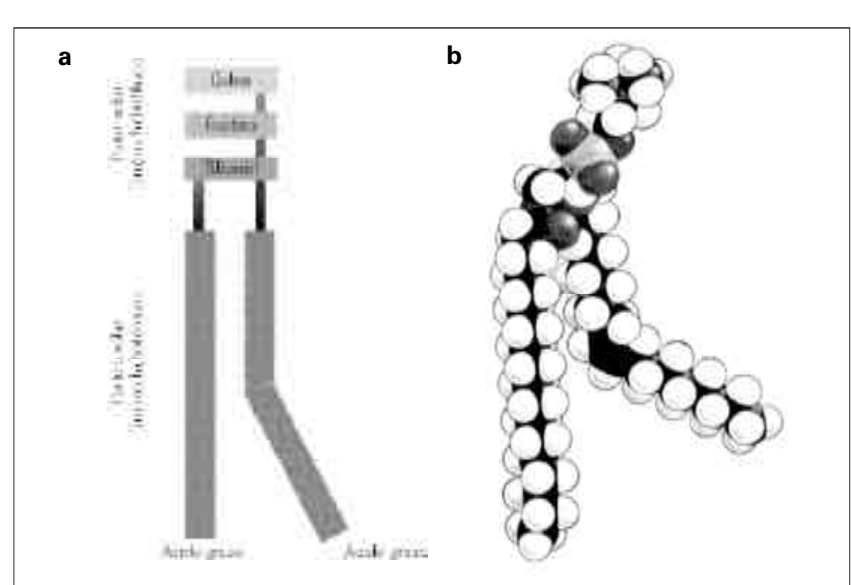

Figura 3. Estructura molecular de los fosfolípidos. Los fosfolípidos son moléculas anfipáticas, que tienen una parte polar (cabeza) y una parte apolar (cola). La parte polar está formada por ácidos grasos de cadena larga. a) Modelo general. b) Modelo atómico [1].

na. La molécula de colesterol es también una molécula asimétrica anfifílica, contiene una parte polar y otra no polar. El colesterol se dispone entre las moléculas de fosfolípidos, orientándose de forma parecida a como lo hacen los fosfolípidos; la parte polar queda encarada a cualquiera de las dos superficies de la membrana celular, mientras que la parte no polar se orienta hacia la parte interna de la membrana. Se sabe que el colesterol tiene un gran efecto sobre la movilidad lateral de los fosfolípidos en las membranas celulares, que se traduce en una disminución de la fluidez de las membranas artificiales. Por otra parte, debe destacarse que el colesterol no se distribuye de manera simétrica en los dos planos o capas de la membrana. Esta distribución asimétrica favorece la curvatura de las membranas celulares que puede ser, en algunos casos, muy acusada como en los eritrocitos.

\section{Glicolípidos}

Los glicolípidos están formados por glicerol, al que se une un par de cadenas de ácidos grasos, y una parte glucídica. La parte glucídica está formada por azúcares simples como la glucosa, o la galactosa, o algunos derivados como la glucosamina o galactosamina. Las dos cadenas de ácidos grasos, al igual que en los fosfolípidos, no son iguales y hay una cadena de ácidos grasos saturada y otra cadena insaturada. Los glicolípidos se localizan exclusivamente en la capa de la membrana plasmática que está en contacto con el espacio extracelular. Los glicolípidos se disponen orientando su parte apolar (cadenas de ácidos grasos) hacia la parte interna de la membrana, mientras que su parte polar queda expuesta hacia el líquido extracelular. Algunos glicolípidos contienen ácido siálico (ácido n-acetilneuramínico) además de los glúcidos simples. Los gangliósidos son especialmente abundantes en algunos tejidos o estructuras como la mielina.

\section{Proteínas}

Si la membrana plasmática de las células estuviera formada exclusivamente por lípidos, el medio intracelular quedaría totalmente aislado del medio extracelular, ya que las características hidrofóbicas de los lípidos no permitirían el paso de soluciones a su través. Las proteínas de la membrana son, por tanto, las moléculas que regulan el paso de iones o sustancias entre ambos lados de la membrana. Las bombas iónicas y los canales iónicos son las proteínas de membrana responsables de dichos procesos. Las características de los canales iónicos se describirán en los párrafos siguientes.

\section{EL POTENCIAL ELÉCTRICO DE LA MEMBRANA PLASMÁTICA [3,4]}

La composición iónica del medio intracelular es distinta a la del medio extracelular. El medio intracelular es rico en potasio, mientras que el medio extracelular es rico en sodio. Esta distribución asimétrica de iones implica la formación, a ambos lados de la membrana, de una diferencia de potencial eléctrico.

Es posible emular en el laboratorio las condiciones de distribución de iones que encontramos en las células (Fig. 4). Se utilizan dos cubetas de experimentación que se comunican a través de una membrana semipermeable, como las de diálisis. La primera cubeta se llena con una solución que contiene una composición parecida al medio extracelular, cloruro de sodio 117 milimolar y cloruro de potasio 3 milimolar; la segunda cubeta se llena con una solución parecida a la del líquido intracelular, 30 milimolar de cloruro de sodio y 90 milimolar de cloruro de potasio. La diferencia de potencial entre ambas cubetas se puede medir mediante un voltímetro sumergiendo los bornes en cada una de ellas. El valor experimental que se obtiene es de $85 \mathrm{mV}$.

Utilizando medios técnicos adecuados como el uso de microelectrodos y micromanipuladores, se comprueba que las células, sea cual sea su naturaleza, presentan una diferencia de potencial, entre su interior y el medio que las rodea. Los valores registrados son muy próximos a los del modelo artificial descrito en el párrafo anterior. Los estudios teóricos desarrollados por Nernst permitieron predecir, a través de una ecuación, cuál es la diferencia de potencial que se establece según la composición iónica de sodio y potasio en el interior y el exterior de la célula. Utilizando la ecuación de Nernst se puede comprobar cómo una pequeña variación de la concentración de potasio extracelular produce un cambio importante en la diferencia de potencial. Asípues, en el ejemplo citado anteriormente, si se aumenta la concentración de potasio extracelular desde 3 a 6 milimolar la diferencia de potencial disminuye desde $85 \mathrm{mV}$ hasta $68 \mathrm{mV}$.

La diferencia de potencial entre el medio extracelular y el medio intracelular se conoce como potencial de membrana o también potencial de reposo. Aunque los iones sodio y potasio son cationes monovalentes, se acordó que la parte intracelular representaba la parte menos positiva o, en otras palabras, más negativa, por lo que el potencial de reposo de una célula se expresa en forma negativa, por ejemplo $-75 \mathrm{mV}$.

En el laboratorio, dos soluciones distintas, en contacto a través de una membrana semipermeable, tienden, al cabo de un cierto tiempo, a mezclarse. En las células, también las distintas soluciones iónicas que separan la membrana plasmática tienden a mezclarse. La relación entre el volumen del líquido extracelular y el medio intracelular es favorable al primero, lo que significa que hay una tendencia a la entrada de sodio al interior de las células y por tanto representa una tendencia a aumentar su concentración intracelular. Si aplicamos la ecuación de Nernst predecimos que la entrada pasiva de sodio debe causar una pérdida de potencial de membrana. La pérdida de potencial de membrana se conoce como despolarización. Para compensar esta pérdida de potencial de reposo, las membranas plasmáticas poseen la bomba de sodio o ATPasa $\mathrm{Na}^{+} / \mathrm{K}^{+}$. La bomba de sodio es una proteína que introduce potasio al interior de la célula y extrae el sodio hacia el espacio extracelular. Este trasiego de iones se produce en contra del gradiente de concentración, lo que significa que el sodio debe desplazarse desde el interior de la célula, en que está a una concentración de $30 \mathrm{mM}$, hasta el medio extracelular en que su concentración es de $117 \mathrm{mM}$, y el potasio debe trasladarse desde el medio extracelular, en que está a una concentración $3 \mathrm{mM}$, hasta el interior de 


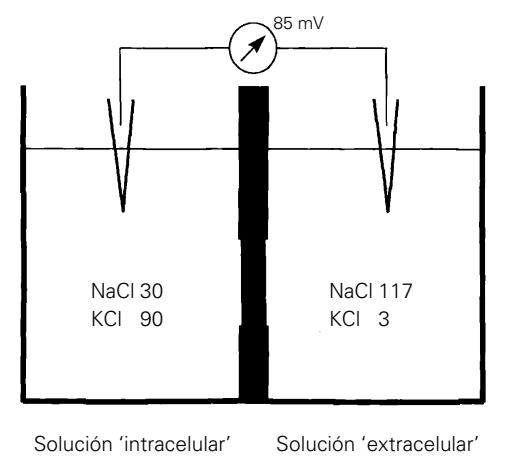

Figura 4. Modelo artificial de distribución de iones. En este modelo artificial se han comunicado dos cubetas a través de una membrana semipermeable. Cada una de las cubetas contiene una solución que imita la composición iónica del medio intracelular y del medio extracelular. La diferencia de potencial eléctrico entre las soluciones se mide a través de los bornes que quedan sumergidos en las dos soluciones. La diferencia de potencial es de $85 \mathrm{mV}$. Variando las concentraciones de sodio y potasio en las dos cubetas se puede modificar la diferencia de potencial.

la célula cuya concentración es de $90 \mathrm{mM}$. Para vencer esta barrera energética que significa moverse contra el gradiente químico, la bomba de sodio utiliza la energía resultante de la hidrólisis del ATP celular. La actividad de las bombas de sodio permite que las células mantengan un potencial de membrana constante.

Algunas células, como las neuronas, las fibras musculares cardíacas, las fibras musculares esqueléticas y las fibras musculares lisas tienen la membrana plasmática excitable. El concepto de membrana plasmática excitable implica que las citadas células conducen señales de tipo eléctrico. Las señales eléctricas son el resultado de los cambios transitorios del potencial de membrana. Los cambios transitorios del potencial de membrana se conocen como potenciales de acción. El potencial de acción dura unos pocos milisegundos, y avanza a lo largo de la membrana. La forma y duración de estos cambios varía de célula a célula. La forma de un potencial de acción de una fibra muscular cardíaca es distinta a la de una neurona. Incluso las neuronas presentan distintas formas de potencial de acción según su naturaleza y localización.

\section{LOS CANALES IÓNICOS}

La generación de los potenciales de acción se debe a la actividad de proteínas específicas de la membrana plasmática conocidas como canales iónicos. Los canales iónicos son proteínas integrales de membrana que permiten el paso de iones a su través (Fig. 5). En la última década, y gracias a las técnicas de biología molecular, se ha descubierto la secuencia de aminoácidos y la estructura de muchos canales iónicos.

Existen dos grandes categorías de canales iónicos: los canales iónicos activados por neurotransmisores (receptores) y los canales iónicos activados por voltaje.

El conocimiento que tenemos actualmente sobre los distintos tipos de canales iónicos se debe a los trabajos realizados por Erwin Neher y Bert Sakmann [5], quienes desarrollaron una nueva técnica conocida como 'patch-clamp' y que les valió el premio Nobel de Medicina y Fisiología. Los amplificadores electrónicos de patch-clamp permiten, a través de un solo microelectrodo, fijar de manera artificial el voltaje de la membranas celulares y registrar la actividad de los canales iónicos. Los amplificadores de patch-clamp

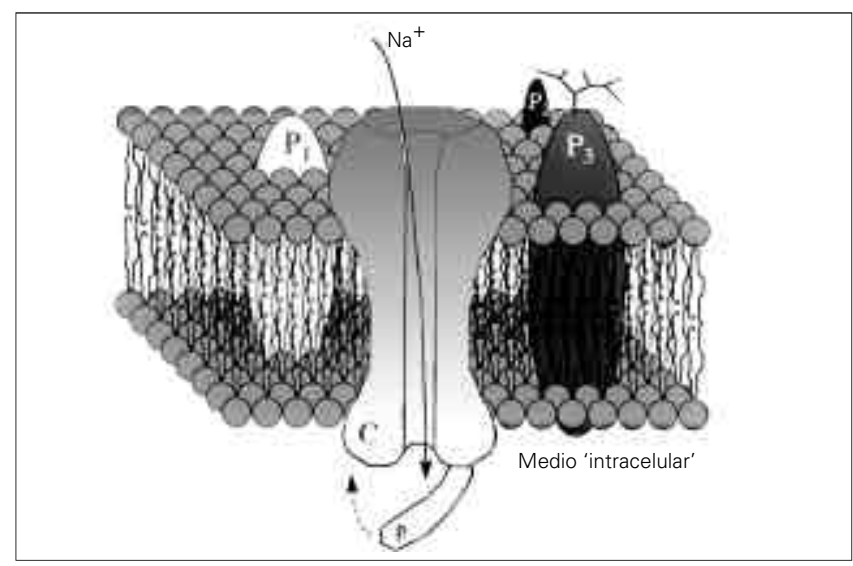

Figura 5. Inserción de los canales iónicos en la membrana plasmática. Los canales iónicos son proteínas integrales de membrana, que presentan un poro que permite el paso de los iones. En el esquema se representan distintas proteínas integrales de membrana señaladas como $P_{1}, P_{2}, P_{3}$, que sobresalen entre los fosfolípidos de la membrana celular. 'El canal iónico $(\mathrm{C})$, es también una proteína integral de membrana que permite el paso de iones a su través. Los cambios de conformación de una parte de esta proteína (p) actúan como una compuerta que permite el paso de los iones y define sus dos estados funcionales: abierto y cerrado. El estado abierto puede desencadenarse por efecto del voltaje al que está sometido el canal iónico, o bien por la acción de neurotransmisores.

son tan sensibles que permiten medir la abertura o cierre de un solo canal iónico (Fig. 6). Los amplificadores de patch-clamp son la única técnica de laboratorio que permite estudiar el comportamiento de una sola molécula aislada. Gracias a la técnica de patch-clamp se ha descubierto que los canales iónicos no sólo están presentes en las células excitables como las neuronas y las fibras musculares, sino en todas las células del cuerpo humano, desde los linfocitos sanguíneos hasta las células epiteliales del tubo digestivo. Gracias a la técnica de patch-clamp, se ha descubierto que las membranas de los orgánulos celulares poseen canales iónicos, y que también las células vegetales tienen canales iónicos.

Los canales iónicos son proteínas que presentan dos estados conformacionales, que corresponden a la abertura y cierre del canal iónico. Un canal iónico abierto permite el paso de iones a su través mientras que un canal iónico cerrado es impermeable a los iones. Las características funcionales de canales iónicos vienen definidos por distintas variables que pueden medirse con gran precisión. Éstas son: la cantidad de corriente eléctrica que pasa a través de un canal iónico, el tiempo que permanece abierto un canal iónico, el potencial eléctrico en que se abren o cierran, la naturaleza de los iones que pasan a su través y finalmente las interacciones farmacológicas a las que son susceptibles.

El primer canal iónico aislado y caracterizado funcionalmente fue el receptor nicotínico a la acetilcolina, que es un complejo de cinco subunidades. Existen cuatro tipos distintos de subunidades, denominadas $\alpha, \beta, \gamma, \delta$. Cada molécula de receptor nicotínico posee una unidad $\beta, \gamma, \delta$ y dos subunidades $\alpha$; sobre cada una de éstas se fija una molécula de acetilcolina, produciendo la abertura del canal iónico. La abertura del canal iónico permite fluir los iones a favor de su gradiente químico, y generar así una corriente de iones. En general, los neurotransmisores excitadores abren canales que permiten el paso de los iones sodio hacia el interior de la célula, produciendo, por tanto, una despolarización. Los receptores para otros neurotransmisores cerebrales como el glutamato, la glicina o el ATP, presentan un notable parecido a la estructura molecular del receptor nicotínico a la acetilcolina.

La otra gran categoría de canales iónicos corresponde a los 


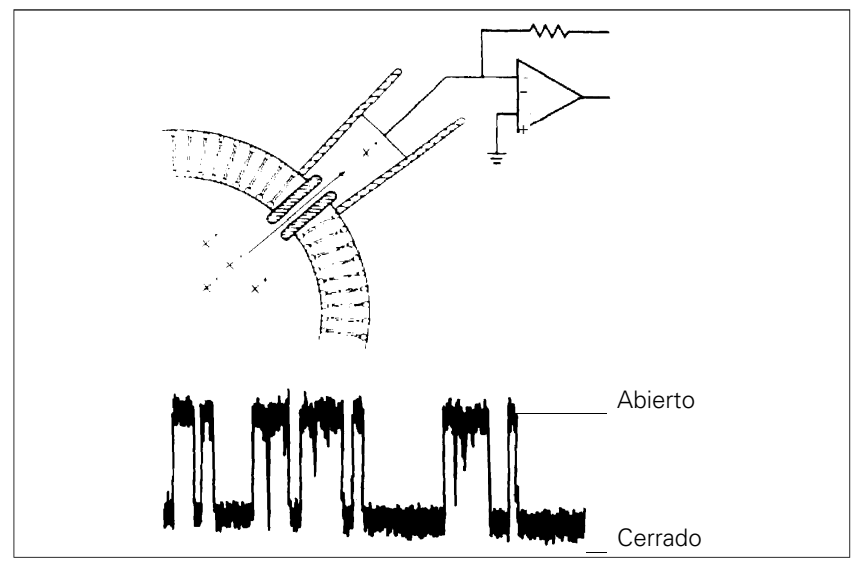

Figura 6. Las pipetas de registro electrofisiológico pueden situarse sobre la superficie de las células, y mediante los amplificadores de patch-clamp se puede registrar la actividad de unos pocos o de un solo canal iónico. En la parte inferior se muestra un registro de la actividad de un canal iónico en el que se puede observar el estado abierto y el estado cerrado [3]

canales iónicos sensibles a los cambios de voltaje de la membrana plasmática. Los canales iónicos activados por el voltaje presentan una gran selectividad para las distintas especies de iones que hay en los líquidos fisiológicos. Existen canales que permiten exclusivamente el paso de sodio, otros canales sólo permiten el paso de potasio, mientras que otros se han especializado en regular el paso del calcio. Por último, también se ha demostrado que existen canales que regulan el paso de los aniones como el cloruro.

En condiciones fisiológicas, el flujo de iones siempre sigue el gradiente químico. Por ejemplo, los canales de sodio, al abrirse permiten el paso del sodio desde el medio extracelular hasta el interior de la célula; por el contrario, los canales de potasio facilitan la salida de potasio de las células, porque el potasio, como se ha mencionado anteriormente, está más concentrado en el interior de la célula. En general podemos asociar grandes funciones a los distintos tipos de canales iónicos. Los canales de sodio tienen como finalidad despolarizar la membrana de las células. Los canales de potasio y los canales de cloruro desempeñan una función opuesta a la de los canales de sodio, dan lugar a la repolarización celular. Los canales de calcio regulan la concentración intracelular de calcio, el cual desempeña un papel determinante en los procesos de secreción celular, y de forma muy especial en la transmisión sináptica.

Dentro de cada una de estas grandes categorías de canales iónicos existen subtipos. Por ejemplo, se han descrito varios tipos de canales de calcio que regulan la transmisión sináptica; se han denominado de tipo $\mathrm{T}$, de tipo L, de tipo $\mathrm{N}$ o de tipo $\mathrm{P}$, según el potencial de membrana en el que se activan, su sensibilidad a fármacos como el nicardipino, nifedipino o el nitrendipino, o a toxinas específicas de algunos invertebrados, o su inactivación a lo largo del tiempo.

Existe una relación causal entre la generación y propagación de los potenciales de acción y la actividad de los canales iónicos. Veamos qué ocurre en una neurona, que recibe una sinapsis de tipo colinérgico. Describiremos dos fases: primera, generación del potencial de acción; segunda, propagación del potencial de acción. La generación del potencial de acción se debe a la acetilcolina liberada por el terminal, que se fija sobre el receptor a la acetilcolina, el cual se abre, pasa sodio a su través hacia el interior de la neurona, lo que provoca la despolarización de una pequeñísima porción de la membrana plasmática. Una vez generado el potencial de acción, se pasa a la fase de propagación. El potencial de acción se propaga de forma parecida a la propagación de la ignición en una mecha pirotécnica: la ignición de un segmento de mecha eleva la temperatura a los niveles necesarios para que empiece a arder la pólvora más cercana. Los canales de sodio son los responsables de la propagación de los potenciales de acción. En la neurona, la despolarización inducida por la acetilcolina provoca la abertura de algunos canales de sodio vecinos del receptor nicotínico, lo que a su vez provoca una despolarización más profunda que afecta a más canales de sodio. Estos cambios en cadena dan lugar a la propagación del potencial de acción. Los cambios de voltaje generados por la abertura de los canales de sodio serán también responsables de su finalización ya que cuando la membrana está muy despolarizada se alcanzan unos voltajes en los cuales los canales de potasio se abren. Los canales de potasio abiertos permiten el flujo de potasio desde el interior de la neurona hacia el exterior, lo que conlleva la repolarización celular o, en otras palabras, se recupera el potencial de membrana inicial, el mismo que poseía la neurona antes de que actuara la acetilcolina liberada por la transmisión sináptica. En conclusión, el potencial de acción se debe a la actividad coordinada de distintos tipos de canales iónicos presentes en la membrana neuronal.

La actividad de los canales iónicos no sólo está controlada por la secuencia de los aminoácidos de las proteínas que los forman, sino que puede variar por transformaciones que se desencadenan durante la actividad celular, como la fosforilación de algunos aminoácidos o la interacción con los lípidos de membrana que están en contacto directo con el canal iónico [6].

\section{CANALES IÓNICOS Y ENVEJECIMIENTO}

Poco se conoce de la variación de la actividad de los canales iónicos durante el desarrollo y durante el envejecimiento. Respecto al desarrollo, se descubrió que el receptor nicotínico a la acetilcolina en los tejidos embrionarios tiene una estructura y actividad distintas a la de los tejidos adultos. En el músculo esquelético adulto hay una pequeña proporción de receptor nicotínico embrionario, el cual se convierte nuevamente en mayoritario en condiciones patológicas como la denervación o la miastenia gravis. Durante el envejecimiento hay un aumento en el número de receptores nicotínicos en las fibras musculares [7] aunque sus propiedades eléctricas elementales (tiempo de abertura del canal, cantidad de corriente eléctrica que fluye por el canal) no varían. Otras funciones del receptor nicotínico sí varían con la edad, por ejemplo disminuye la afinidad de la acetilcolina por las subunidades $\alpha$ [8].

Otros receptores de neurotransmisores cerebrales como GABA (ácido gamma aminobutírico), no varían tampoco sus propiedades eléctricas elementales (tiempo de abertura del canal, cantidad de corriente eléctrica que fluye por el canal). Los receptores de GABA están ligados a receptores de las benzodiacepinas. En condiciones fisiológicas las benzodiacepinas aumentan el efecto de GABA. En los animales experimentales envejecidos el efecto potenciador de las benzodiacepinas sobre el receptor de GABA es superior al que tiene en los animales jóvenes [9].

Respecto a los cambios de la actividad de los canales de calcio cabe señalar que se activan más rápidamente y cambian sus propiedades farmacológicas durante la fase de maduración de las neuronas granulares del cerebelo de ratas [10]. Los canales de calcio se activan más fácilmente durante la vejez y en los procesos de demencia [11]. El bloqueo farmacológico de los canales de calcio aumenta la memoria inmediata de animales viejos [12]. Alguno de estos agentes bloqueantes de los canales de calcio, como las dihidropiridinas, son capaces de disminuir la actividad de los canales de calcio por vías indirectas, ya que su efecto se 
debe a su inserción con la bicapa lipídica de la membrana y no a su interacción directa con las proteínas. En modelos de membranas artificiales la acción de la 1,4 dihidropiridina depende de la concentración de colesterol, lo cual indica que la actividad de los canales de calcio puede modificarse por su interacción con el colesterol de las membranas celulares neuronales [13]. Los modelos experimentales han permitido reproducir, en parte, algunos fenómenos relacionados con el aumento de la entrada de calcio en las neuronas a través de los canales de calcio voltajedependientes, durante los procesos de envejecimiento cerebral [14].

Otras posibles vías de entrada de calcio en las neuronas están relacionadas con los receptores a glutamato, que se comportan como un canal iónico, el cual se abre cuando se une a glutamato y permite el paso de sodio y también de calcio hacia el interior de la célula. La sobreactivación de los receptores a glutamato implica un aumento en la concentración intracelular de calcio.

$\mathrm{El}$ aumento incontrolado del calcio intracelular de las neuronas conduce a su muerte, que podría estar relacionada con la muerte neuronal que se da, de manera fisiológica, durante el desarrollo pre- natal del sistema nervioso. La muerte celular fisiológica se conoce como apoptosis y viene precedida de un aumento de los niveles intracelulares de calcio, que a su vez reflejan la activación de distintos tipos de canales iónicos. La activación tardía de algunos canales iónicos podría dar lugar a la activación de fenómenos apoptóticos que desembocan en la muerte neuronal y puede representar la base neurológica de procesos degenerativos como las enfermedades de Parkinson, de Alzheimer y de demencias de origen vascular.

En conclusión, las membranas celulares están compuestas por lípidos sobre los que se insertan los canales iónicos que dirigen y regulan la actividad de las neuronas. La activación descontrolada de los canales iónicos, puede ser, al menos en algunos casos, responsable de la iniciación de los procesos neurodegenerativos. La trascendencia social de las enfermedades neurodegenerativas en las sociedades occidentales ha hecho que en Europa y en Estados Unidos se haya declarado la presente década de los noventa como la década del cerebro, para estimular la investigación de los mismos y tratar de hallar las terapéuticas que los eliminen, o en su defecto, reduzcan sus consecuencias.
1. Alberts B, Bray D, Lewis J, Raff M, Roberts K, Watson JD. The molecular biology of the cell. New York and London: Garland Publishing; 1994

2. Darnell J, Lodish H, Baltimore D. Molecular cell biology. New York: Scientific American Books; 1990.

3. Levitan IB, Kaczmarek LK. The Neuron. Oxford: Oxford University Press; 1991.

4. Nicholls JG, Martin AR, Wallace BG. From neuron to brain. Sunderland, Massachusets: Sinauer Associates; 1992.

5. Hamill OP, Marty A, Neher E, Sakmann B, Sigworth FJ. Improved patch-clamp techniques for high resolution current recording from cells and cell-free membrane patches. Pflugers Arch 1981; 391: 85-100.

6. Barrantes FJ. Structural-functional correlates of the nicotinic acetylcholine receptor and its lipid microenvironment. FASEB-J 1993; 7: 1460-7.

7. Smith DO, Emmerling M. Biochemical and physiological consequences of an age related increase in acetylcholinesterase activity at the rat neuromuscular junction. J Neurosci 1988; 8: 3011-7.

8. Smith DO, Chapman MR. Acetylcholine receptor binding properties at the rat neuromuscular junction during aging. J Neurochem 1987; 48: 1834-41.

\section{MEMBRANA NEURONAL Y ENVEJECIMIENTO. ASPECTOS ELECTROFISIOLÓGICOS}

Resumen. Introducción. Las membranas celulares están formadas por lípidos y proteínas. Por su naturaleza hidrofóbica, los fosfolípidos aíslan el medio intracelular y el extracelular. Desarrollo. El medio extracelular es una solución enriquecida en iones de sodio, mientras que el medio intracelular es rico en iones de potasio. De acuerdo con las leyes de la química, la distribución asimétrica de iones produce una pequeña diferencia de potencial entre el interior y el exterior celular. Todas las células del cuerpo humano presentan esta pequeña diferencia de potencial que se sitúa alrededor de $-60 \mathrm{mV}$. Otro componente de las membranas celulares son las proteínas. Algunas de ellas -las bombas iónicas o ATPasas- mantienen la distribución asimétrica de los iones. Otras proteínas de membrana-los canales iónicos-permiten el paso selectivo de iones entre el medio intracelular y extracelular. Las técnicas de electrofisiología celular (patch clamp) permiten medir el paso de iones a través de una sola molécula. Cada canal iónico permite el paso de una sola especie iónica. Las células contienen canales iónicos que son transitoriamente permeables a los iones sodio, potasio, calcio y cloruro. La excitabilidad neuronal depende de los canales iónicos. Las neuronas presentan un distinto comportamiento eléctrico en las distintas fases de su vida. Los cambios en la actividad eléctrica de las neuronas vienen determinados por la actividad de los canales iónicos y su interacción con su entorno lipídico. Conclusión. Se realizan esfuerzos investigadores para relacionar los cambios de comportamiento de los canales iónicos en el proceso de envejecimiento de las membranas neuronales [REV NEUROL 1999; 29: 1083-8].

Palabras clave. Canales iónicos. Envejecimiento. Neurodegeneración.
9. Griffith WH, Murchison DA. Enhancement of GABA-activated membrane currents in aged Fischer 344 rat basal forebrain neurons. J Neurosci 1995 ; 15 : 2407-16.

10. Rossi P, D'Angelo E, Magistretti J, Toselli M, Taglietti V. Age-dependent expression of high-voltage activated calcium currents during cerebellar granule cell development in situ. Pflugers Arch 1994; 429: 107-16.

11. Landfield PW. Increased hippocampal $\mathrm{Ca}^{2+}$ channel activity in brain aging and dementia. Hormonal and pharmacologic modulation. Ann N Y Acad Sci 1994; 747: 351-64.

12. Levere TE, Walker A. Old age and cognition: enhancement of recent memory in aged rats by the calcium channel blocker nimodipine. Neurobiol Aging 1992; 13: 63-6.

13. Masson RP. Probing membrane bilayer interactions of 1,4-dihydropyridine calcium channel blockers. Implications for aging and Alzheimer's disease. Ann N Y Acad Sci 1994; 747: 125-39.

14. Thibault O, Mazzanti ML, Blalock EM, Porter NM, Landfiled PW. Single-channel and whole cell studies of calcium currents in young and aged rat hippocampal slice neurons. J Neurosci Methods 1995; 59: 77-83.

\section{MEMBRANA NEURONAL E ENVELHECIMENTO. ASPECTOS ELECTROFISIOLÓGICOS}

Resumo. Introdução. As membranas celulares estão formadas por lípidos e proteínas. Pela sua natureza hidrofóbica, os fosfolípidos isolam o meio intracelular e o extracelular. Desenvolvimento. O meio extracelular é uma solução enriquecida em iões de sódio, enquanto que o meio intracelular é rico em iões de potássio. De acordo com as leis da química, la distribuição assimétrica de iões origina uma pequena diferença de potencial entre o interior e o exterior celular. Todas as células do corpo humano apresentam esta pequena diferença de potencial, situada à volta dos $-60 \mathrm{mV}$. Outro componente das membranas celulares é as proteínas. Algumas delas -as bombas iónicas ou ATPases-mantêm a distribuição assimétrica dos iões. Outras proteínas de membrana-os canais iónicos-permitem a passagem selectiva de iões entre o meio intracelular e extracelular. As técnicas electrofisiológicas (patch clamp) aplicadas aonível celularpermitem-nos medir a passagem de iões através de uma única molécula. Cada canal iónico permite a passagem de uma única espécie iónica. As células contêm canais iónicos que são transitoriamente permeáveis aos iões sódio, potássio, cálcio e cloreto. A excitabilidade neuronal depende dos canais iónicos. Os neurónios apresentam um diferente comportamento eléctrico nas diferentes fases da sua vida. As mudanças na actividade eléctrica dos neurónios são determinadas pela actividade dos canais iónicos e pela sua interacção com o seu envolvente lipídico. Conclusão. Fazem-se esforços na investigação para relacionar as mudanças de comportamento dos canais iónicos com o processo de envelhecimento das membranas neuronais [REV NEUROL 1999; 29: 1083-8]. Palavras chave. Canais iónicos. Envelhecimento. Neurodegeneração. 